\title{
Challenges and Current Status of the Biological Treatment of PFAS-Contaminated Soils
}

\author{
Esmaeil Shahsavari ${ }^{1 * \dagger}$, Duncan Rouch ${ }^{1 \dagger}$, Leadin S. Khudur ${ }^{1 \dagger}$, Duncan Thomas ${ }^{1}$, \\ Arturo Aburto-Medina ${ }^{1}$ and Andrew S. Ball ${ }^{1,2}$ \\ 'School of Science, RMIT University, Bundoora, VIC, Australia, ${ }^{2}$ ARC Training Centre for the Transformation of Australia's \\ Biosolids Resource, RMIT University, Bundoora, VIC, Australia
}

Per- and polyfluoroalkyl substances (PFAS) are Synthetic Organic Compounds (SOCs) which are of current concern as they are linked to a myriad of adverse health effects in mammals. They can be found in drinking water, rivers, groundwater, wastewater, household dust, and soils. In this review, the current challenge and status of bioremediation of PFAs in soils was examined. While several technologies to remove PFAS from soil have been developed, including adsorption, filtration, thermal treatment, chemical oxidation/reduction and soil washing, these methods are expensive, impractical for in situ treatment, use high pressures and temperatures, with most resulting in toxic waste. Biodegradation has the potential to form the basis of a cost-effective, large scale in situ remediation strategy for PFAS removal from soils. Both fungal and bacterial strains have been isolated that are capable of degrading PFAS; however, to date, information regarding the mechanisms of degradation of PFAS is limited. Through the application of new technologies in microbial ecology, such as stable isotope probing, metagenomics, transcriptomics, and metabolomics there is the potential to examine and identify the biodegradation of PFAS, a process which will underpin the development of any robust PFAS bioremediation technology.

\footnotetext{
Keywords: PFAS-contaminated soils, bioremediation, mycoremediation, bioaccumulation, bacteria, phytoremediation
}

\section{INTRODUCTION}

As a result of continued production and use, per- and polyfluoroalkyl substances (PFAS) have become widespread in the environment, including drinking water, rivers, groundwater, wastewater, household dust, and soils (Kim et al., 2007; Eriksson and Karrman, 2015; Shi et al., 2015; Eriksson et al., 2017; Von Der Trenck et al., 2018). PFAS are highly stable organic compounds that contain multiple carbon-fluorine bonds. They are used in various commercial products, including aqueous fire-fighting foams and products with non-stick coatings. These compounds are also likely to be present in foods (Schaider et al., 2017) and are known to be present in humans, including pregnant women (Lauritzen et al., 2016).

Human exposure to PFAS occurs through several pathways, including ingestion of contaminated drinking water, food and household dust, inhalation of indoor air, and contact with other contaminated media (Trudel et al., 2008). Drinking water sources include rivers, lakes and groundwater may also be contaminated with PFAS originating from industrial sources. There may 
also be significant exposure risk from PFAS-contaminated sewage sludge (biosolids) and recycled water from wastewater treatment plants, which are often used in agriculture, with exposure through contaminated soils and crop foods (Sunderland et al., 2019). PFAS have been shown to have bioaccumulation potential, which tends to increase with increasing chain length. Specific PFAS compounds have been shown to impact human health through altered kidney and thyroid function, immunosuppression and deleterious effects on reproduction and development. Perfluorooctane sulfonate (PFOA)-related chronic diseases include kidney and testicular cancers, ulcerative colitis, and high cholesterol have also been observed (Darrow et al., 2013; Steenland et al., 2013; Starling et al., 2017; Sunderland et al., 2019). PFOS and PFOA are readily absorbed through the gut and are not metabolized, meaning body loads become excessive before they are excreted. PFAS are believed to act as endocrine disruptors through alterations in estrogen- and androgenreceptor functions (Mora et al., 2017). Research conducted by Tao et al. found that PFOS and PFOA accumulate in the serum of adults and blood of newborn babies, which indicates that breast milk is a major pathway for transferal (Tao et al., 2008a,b). Research indicated that the milk of mothers who have given birth to multiple children tend to have slightly higher levels of PFAS (Mora et al., 2017).

PFAS are considered to be stable and amphiphilic, exhibiting both hydrophobic and lipophobic tendencies (Giesy et al., 2010) resulting in ready accumulation within lipids (fats) and proteins (Mora et al., 2017; Seo et al., 2018). Based on the above health issues, there is an urgent need to remove these compounds from soils. Current methods to remove PFAS from contaminated soils are expensive, impractical for in situ treatment, use high pressure and temperatures, and/or result in toxic waste. Biodegradation has the potential to form the basis of a cost-effective, large scale in situ remediation strategy for PFAS. However, information about the biodegradation of PFAS by fungal and bacteria is limited. Consequently, this review aims to review chemical properties, the source of PFAS contamination in soils and summarize the remediation technologies, focussing on the potential of bioremediation for the safe and effective removal of PFAS from soils.

\section{CHEMICAL PROPERTIES OF PER-AND POLYFLUOROALKYL SUBSTANCES (PFAS) COMPONENTS}

Per-and polyfluoroalkyl substances (PFAS) are a group of synthetic man-made compounds manufactured for their ability to interact between two immiscible fluid phases acting as a surfactant (Buck et al., 2011; Rahman et al., 2014). PFAS are highly polar and contain strong carbon-fluorine bonds (CF) which display unique amphiphilic properties (Figure 1). Generally, most PFAS exhibit (i) high thermal resistance, (ii) high chemical stability, and (iii) resistance to biotic degradation (Buck et al., 2011; Lindstrom et al., 2011; Rahman et al., 2014). Two broad categories of PFAS have been defined:
- Perfluoroalkyl substances typically comprise of short and long carbons chains $(\mathrm{C} 2-\mathrm{C} 13+)$ and have a charged functional group head which is attached to one end. Generally, this functional group will be a carboxylic or sulfonic acid. Fluorine atoms attach to all bonding sites on the carbon chain except for the last carbon group head forming multiple carbon-fluorine (C-F) bonds (Figure 1). C-F bonds have the dissociation energy of $450 \mathrm{~kJ} \mathrm{~mol}^{-1}$ compared to carbon-chlorine and carbon-bromine bonds at 330 and $194 \mathrm{~kJ} \mathrm{~mol}^{-1}$, respectively (Parsons et al., 2008).

- Polyfluoroalkyl substances are not fully fluorinated. These substances have at least one lapse in the chain which is not a fluorinated atom-typically hydrogen or oxygen-which attaches to one of the carbon-chain tails. Polyfluoroalkyl chains contain carbon-hydrogen $(\mathrm{C}-\mathrm{H})$ bonds which create weak chains that are susceptible to biotic or abiotic degradation (Buck et al., 2011).

Three specific PFAS compounds, perfluorooctane sulfonate (PFOS), perfluorooctane acid (PFOA) and perfluorohexane sulfonate (PFHxS) (Figure 1) are known to have been contained in much older Aqueous Film Forming Foams (AFFF). Within environmental $\mathrm{pH}$ values, both PFOA and PFOS exist as anions (Rahman et al., 2014). Generally, PFAS do not degrade in water or soil under normal conditions, although it is thought that they can undergo physiochemical changes and breakdown into smaller alkyl chains (Teaf et al., 2019). The physicochemical properties of these three major PFAS compounds are presented in Table 1 and further discussed below:

- Perfluorooctane Sulfonate (PFOS), CAS number 1763-231 , is a completely fluorinated compound that contains eight carbon atoms and a sulfonate group head. PFOS has been used as coatings and protectants. PFOS is produced commercially from perfluorooctanesulfonly fluoride (POSF) which was used as an intermediate to produce other fluorochemicals. PFOS is formulated by $\mathrm{C}_{8} \mathrm{HF}_{17} \mathrm{O}_{3} \mathrm{~S}_{1}$ which has a molecular mass of $500.13 \mathrm{~g} / \mathrm{mol}$. PFOS is produced through Simons ElectroChemical fluorination (SECF), which produces $70 \%$ linear chains and $30 \%$ branched chains isomers. PFOS can also be created through telomerization which produces linear chains. As PFOS has major impurities in the form of other POSFderived fluorochemicals it can be formed in the environment through the degradation of POSF-based products (Buck et al., 2011).

- Perfluorooctanoic Acid (PFOA), CAS number 335-67-1, is a completely fluorinated organic acid with seven-carbon (C7) atoms and a carboxyl functional group head. PFOA has been a main constituent of AFFFs, as well as non-stick coats, and waterproofing. PFOA is formulated by $\mathrm{C}_{8} \mathrm{HF}_{15} \mathrm{O}_{2}$ which has a molecular mass of $414.07 \mathrm{~g} / \mathrm{mol}$ (Buck et al., 2011).

- Perfluorohexane Sulfonate (PFHxS), CAS number 355-46-4, has 6 carbons (C6) and is a completely fluorinated organic acid that is capable of repelling oil and water which have been used in the manufacturing of AFFF. PFHxS displays similar properties to both PFOS and PFOA. PFHxS is formulated by 
(i)

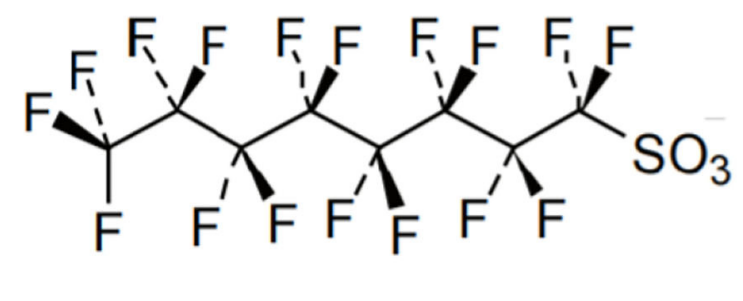

(ii)
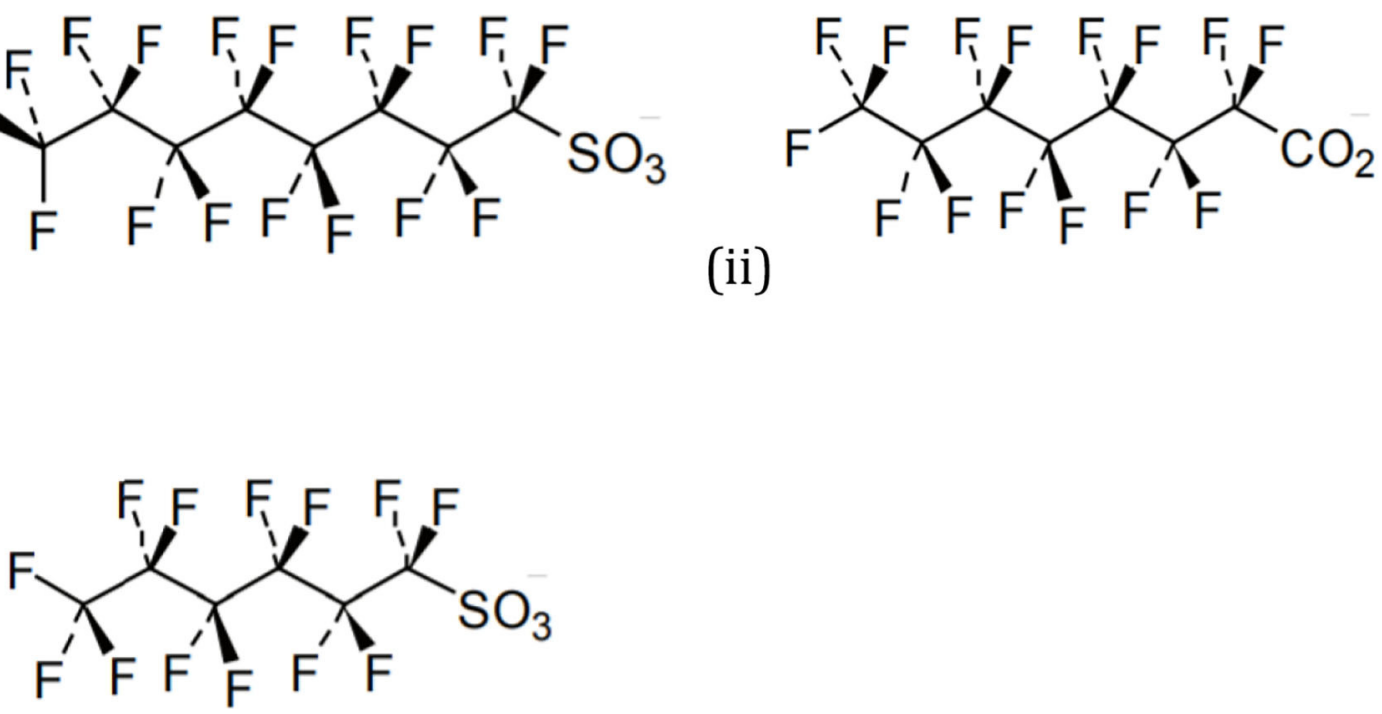

(iii)

FIGURE 1 | Structure of PFAS (i) PFOS (ii) PFOA, (iii) PFHxS structure (Buck et al., 2011).

TABLE 1 | Physiochemical properties of PFAS (Buck et al., 2011).

\begin{tabular}{llll}
\hline Characteristic & PFOS & PFOA & PFHxS \\
\hline Appearance & White powder (potassium salt) & White to off-white powder & White crystalline powder \\
Melting point & $>400^{\circ} \mathrm{C}$ (potassium salt) & $54.3^{\circ} \mathrm{C}$ & No data \\
Boiling point & $258-260^{\circ} \mathrm{C}$ & $192.4^{\circ} \mathrm{C}$ & $114.7^{\circ} \mathrm{C}>400^{\circ} \mathrm{C}$ \\
$\begin{array}{l}\text { Density } \\
\text { Water }\end{array}$ & $\sim 0.6$ (potassium & $1.7292 \mathrm{~g} / \mathrm{mL}$ at $20^{\circ} \mathrm{C}$ & $1.84 \mathrm{~g} / \mathrm{mL}$ at $20^{\circ} \mathrm{C}$ \\
solubility & $519 \mathrm{mg} / \mathrm{L}$ at $20^{\circ} \mathrm{C} ; 680 \mathrm{mg} / \mathrm{L}$ at $24-25^{\circ} \mathrm{C}$ & Soluble, $9.5 \mathrm{~g} / \mathrm{L}$ at $25^{\circ} \mathrm{C}$ & Slightly soluble \\
$\begin{array}{l}\text { Organic } \\
\text { solvent }\end{array}$ & $56 \mathrm{mg} / \mathrm{L}$ & Soluble in polar organic solvents & No data \\
solubility & & & Not measured \\
Log Kow & Not measurable & 6.30 (estimated) in octanol-water mixture & 0.14 \\
pKa: & -3.3 (estimated) & Debated; values of 2.8 and 3.8 have been & \\
& & reported. O.5 has been estimated. &
\end{tabular}

$\mathrm{C}_{6} \mathrm{HF}_{13} \mathrm{O}_{3} \mathrm{~S}$ and has a molecular mass of $400.12 \mathrm{~g} / \mathrm{mol}$ (Buck et al., 2011).

Based on the physiochemical properties, PFAS have been identified to have bioaccumulation potential, which tends to increase with increasing chain length. Most health research has been conducted on individuals with high levels of PFAS accumulated in their organs due to work on containment sites, airbases, and in response firefighting. A significant number of PFOA-related chronic diseases which include kidney and testicular cancers, ulcerative colitis, high cholesterol have been reported among PFAS-exposed individuals (Darrow et al., 2013; Steenland et al., 2013; Starling et al., 2017; Sunderland et al., 2019). PFOS and PFOA are readily absorbed through the gut and are not metabolized, meaning body loads become excessive before they are excreted. PFAS are believed to act as endocrine disruptors through the alteration in estrogen- and androgenreceptor functions (Mora et al., 2017). Human exposure to PFAS, produced by industry, occurs through ingestion of contaminated drinking water, food and household dust, inhalation of indoor air, and contact with other contaminated media (Trudel et al., 2008). Drinking water sources include rivers, lakes, and ground water, which can all be contaminated from industrial sources. In addition, there appears a significant exposure risk from contaminated treated sewage sludge (biosolids), as fertilizer, and recycled water from wastewater treatment plants, which are often used in agriculture, providing potential human exposure through contaminating crop foods (Sunderland et al., 2019).

\section{SOURCES OF CONTAMINATION OF PFAS AND FATE IN THE ENVIRONMENT}

The following section describes major sources of PFAS in the environment. 


\section{Aqueous Film Forming Foams (AFFFs)}

Aqueous Film Forming Foams (AFFFs) are intended to be used on flammable liquid fires through the process of combining hydrocarbon foaming agents with fluorinated surfactants when mixed with water (Backe et al., 2013). This creates interfacial tension that spreads across the surface of a hydrocarbon fuel, which extinguishes the flame, and forms a vapor barrier between the fuel and atmospheric oxygen, preventing re-ignition (Backe et al., 2013; Weiner et al., 2013; Harding-Marjanovic et al., 2015). The fluorotelomer AFFF, although not directly made with PFOA, and therefore less toxic to the environment has precursors that breakdown into PFOA in the natural environment (Backe et al., 2013; Weiner et al., 2013; Harding-Marjanovic et al., 2015). Typically, fluorotelomer based AFFF contains short-chain (C6) PFAS which can range from 50 to $98 \%$ short chains balanced with long-chain PFAS which can break down to PFOA.

Fire training facilities undergo extensive and prolonged use of AFFFs, which has caused large volumes of PFAS to be released into adjacent soils during short periods (Dauchy et al., 2019). From there PFAS leaches into groundwater supplies. Soils that do not contain high amounts of Total Organic Matter (TOC) through a lack of vegetation, land clearing, and anthropogenic abuse make it difficult for the chemicals to bind within the soil substrate (Allred et al., 2015; Gallen et al., 2018). Dauchy et al. (2019) sampled 44 soil cores and 17 groundwater samples from a firefighting drill sites active for more than 30 years and detected PFOS, 6:2 FTSA and 6:2 FTAB as the most predominant PFAS in surface soil; the highest total concentrations detected were $357 \mu \mathrm{g} \mathrm{g}^{-1}$, despite the presence of clay layers. However, the highest total PFAS concentrations were detected in the wells at the perimeter of the firefighter training site as well as the spring located downgradient of the groundwater flow. These concentrations ranged from 300 to $8,300 \mathrm{ng} \mathrm{L} \mathrm{L}^{-1}$; $6: 2$ FTAB was detected in water table $20 \mathrm{~m}$ belowground indicating these chemicals are not contained.

\section{Landfill Leachate}

Landfills are designed to undergo large amounts of decomposition from natural and man-made organic compounds. Realistically, landfill serves as temporal and spatial storage. In a landfill, soil chemistry is heavily compromised which impacts natural degradation processes due to the number and nature of pollutants present. PFAS within waste can become mobile and leach into pore water creating contaminated leachate. Fortunately, modern sanitary landfills typically have stringent mechanisms for preventing and mitigating leachate from entering groundwater. However, the controlled discharge of leachate to wastewater treatment plants is allowed. Reinforcement of smaller and older sites to stop the threat of local point source contamination into surrounding soil and groundwater is paramount. PFAS will continue to persist in the landfill and continue to increase over time (Gallen et al., 2018). Studies examining landfill leachate confirmed that PFHxS was detected at high concentrations (mean 1,700 ng $\mathrm{L}^{-1}$; range 73-25,000 ng $\mathrm{L}^{-1}$ ); PFOA contamination was on average $690 \mathrm{ng} \mathrm{L}^{-1}$ (range of 17-7,500 $\mathrm{ng} \mathrm{L}^{-1}$ ) and PFOS was detected at concentrations with a mean of $310 \mathrm{ng} \mathrm{L}^{-1}$ (range
13-2,700 ng L ${ }^{-1}$ ). Samples from sites with higher levels of PFAS profiles generally had greater proportions of construction and demolition waste. Dealing with landfill chemistry will require novel treatment pathways to deal with the existing PFAS loads on-site (Hamid et al., 2018).

Hepburn et al. (2019) stated that groundwater systems are at risk from increased urban re-development on former industrial land and this would lead to increased human exposure to PFAS. Their research indicates that legacy landfills are poorly constructed in major Australian urban developmental precincts. PFOS, PFHxS, PFOA, and PFBS were all detected in samples surrounding 13 sample locations including sites directly on waste material and down-gradient of landfills indicating evidence of leachate contamination. Many urban areas contain unknown amounts of legacy landfills which may lack any former leachate control, increasing the probability of contaminating local aquifers.

\section{Biosolids and Recycled Water}

Point sources of PFAS transmission to agriculture occurs through the application of recycled water from wastewater treatment plants, landfill leachates and biosolids applied to agricultural land (Blaine et al., 2014; Ghisi et al., 2019). Venkatesan and Halden (2014) monitored soil amended with PFAS-containing biosolids over 3 years. They observed a loss of short-chain PFAS compounds within 100 days of application, due mainly to groundwater and surface water leaching. In a laboratory-based study by Allred et al. (2015) on the physical and biological release of PFAS from landfill leachate, they reported that increased leaching occurred from biological reactors under methanogenic conditions compared to abiotic reactors.

Once in agricultural lands, PFAS can be taken into the root systems of plants including cereals, fruits, and vegetables. PFAS with higher chain lengths are usually restricted to the roots, whereas shorter chains compounds can extend further (Ghisi et al., 2019). Generally, the physicochemical properties of the soil together with the plant uptake system will determine the rate and accumulation of PFAS; however, generally, PFOS accumulates at greater concentrations compared to PFOA. Pérez et al. (2013) showed that the PFAS in human tissue was 263 and $807 \mathrm{ng} \mathrm{g}^{-1}$ in the kidney and lung. In plants, the amount varied; however, most experiments used the spike method for contamination of soil. For example, Stahl et al. (2009) showed that ryegrass accumulated PFAS ranged between 408 and 7,520 $\mu \mathrm{g} \mathrm{kg}^{-1}$ dry weight when the soil was contaminated with $0-$ $50 \mathrm{mg} \mathrm{kg}^{-1}$ PFAS.

\section{PFAS in Soil Systems}

As a consequence of these major sources of PFAS, these compounds are almost ubiquitously detected in the environment (Xiao et al., 2015; Lu et al., 2018). Research has indicated that soil organic carbon content is the dominant solid-phase parameter which affects the adsorption of PFAS. Solid matrices influence the environmental fate of hydrophobic organic contaminants (Higgins and Luthy, 2006). However, the different behavior of PFAS in comparison to traditional ionisable organic pollutants is due to their hydrophobic and hydrophilic functionalities 
(Li et al., 2018). Adsorption to soil or sediment can occur through two-mechanisms: interaction of their hydrophobic fluorinated carbon tails with the organic carbon fraction of the soil, or to a lesser extent by electrostatic interactions of the polar head group with the charged clay fraction (Kucharzyk et al., 2017). Longer-chained PFAS appear to sorb to soils more readily. PFAS with sulfonate groups sorb more than carboxylates. In comparison to PFOS which has a higher sorption capacity, PFOA is usually found in the dissolved phase. Perfluorinated acids appear to bind to soils with higher total organic carbon (TOC) and iron oxide concentrations; Li et al. (2018) achieved an adsorption equilibrium in $\sim 48 \mathrm{~h}$. Their results indicated that both PFOS and PFOA adsorption are influenced by TOC, proteins and saccharides. Similarly, iron and aluminum oxides also appear to be key parameters for adsorption of PFAS. Some forest soil vegetation shows greater ability to accumulate PFAS; the background levels of PFOA and PFOS in 28 forest soils suggested that PFOA concentrations were greater in precipitation at higher altitudes (Cabrerizo et al., 2018). In contrast, the concentration of PFOA in temperate grasslands appears to be much lower (Wang et al., 2018).

In summary, both bioaccumulation and translocation of PFAS occur from both natural terrestrial and aquatic environments and anthropologically built-up areas (Giesy and Kannan, 2001, 2002; Giesy et al., 2010; Xiao et al., 2012; Hu et al., 2016; Hepburn et al., 2019). The distribution of PFAS is enhanced by leaching and discharge into adjacent locations from treatment plants and urbanized redevelopments; eventually reaching oceans, including the North Pacific and the Arctic Ocean (Cai et al., 2012; Hepburn et al., 2019). However in addition, PFAS are now thought to be able to travel through airborne particles and wet and dry atmospheric deposition (Nakayama et al., 2019).

There is only limited information regarding the fate of PFAS in the environment. This is in part due to the difficulty associated with the detection of PFAS in the environment. Avoiding cross-contamination in the sample is difficult due to ambient atmospheric contamination. Most materials will at some point directly come in contact with fluorocarbons (Nakayama et al., 2019).

\section{REMEDIATION APPROACHES}

Technological approaches looking at the removal of PFAS from waste streams or contaminated environments tend to be expensive or impractical for the in situ removal of the contamination (Kucharzyk et al., 2017) (Table 2). Energyintensive methods, such as high pressures and temperatures can disrupt and harm the balance of delicate ecosystems. Nonenergy-intensive technologies such as granular activated carbon adsorption, sonolysis (generating chemical reactions using an acoustic field in a solution) and reverse osmosis have all shown some potential application for PFAS removal during field studies (Kucharzyk et al., 2017; Sorengard et al., 2019). Unfortunately, however, most treatment methods appear to collect rather than dismantle the $\mathrm{C}-\mathrm{F}$ bonds, resulting in a residue containing PFAS that inevitably needs to be placed in a landfill.

Several methods, including adsorption, filtration, thermal, chemical oxidation/reduction and soil washing have been developed for the removal of PFAS from environments. An outline of these approaches is shown in Table 2. Like all methods, there are both advantages and disadvantages related to each method. For example, soil washing is an ex situ technology which requires low technology input. However, it is expensive and may lead to water contamination (de Bruecker, 2015). These technologies have been thoroughly reviewed (Kucharzyk et al., 2017; Mahinroosta and Senevirathna, 2020). While some of these technologies have shown promising outcomes in laboratorybased studies, their cost-effectiveness, field applicability and feasibility are open to question (Mahinroosta and Senevirathna, 2020). Current commercial methods for remediating PFAScontaminated environments, based on the use of one or more of the above treatments are only available for groundwater and not soils. There is therefore an urgent need to develop methods for the in situ bioremediation in the soil at sites contaminated by PFAS. Chemical and physical methods tend to be more expensive than bioremediation approaches, since bioremediation often treats contamination in place, allowing post-clean-up costs to be substantially reduced (Shahsavari et al., 2019).

Bioremediation, which is the use of a biological agent to breakdown contaminants, could represent a simple, environmentally safe and cost-effective technology to treat PFAS-contaminated soils. The commercial application of bioremediation has been successfully applied to remediate a variety of organic contaminants such as petroleum hydrocarbons, chlorinated substances and pesticides (Adetutu et al., 2015; Uqab et al., 2016; Khudur et al., 2019). However, the ability of biological agents to degrade PFAS is poorly studied (Kucharzyk et al., 2017).

\section{Bioremediation Options}

Biodegradation of PFAS may involve enzymes that directly remove fluorine atoms from these compounds either (i) by adding oxygen across the F-C bond, i.e., oxidation, or (ii) adding electrons across the $\mathrm{F}-\mathrm{C}$ bond, i.e., reduction, allowing other normal assimilation enzymes to breakdown the rest of the compound. The F-C bond is very strong and therefore difficult to destroy, which leads to its environmental stability. Therefore, it significant energy is required to catalyze reaction; biologically this can be provided via oxidative or reductive processes. There are known microbes that can break a F-C bond, either under aerobic or anaerobic conditions (Goldman and Milne, 1966; Tiedt et al., 2016, 2017); these are further discussed below.

It has been shown that some bacteria are able to bioaccumulate PFAS in aerobic and to a lesser degree, anaerobic conditions (Table 3); most of these bacteria have been identified as Pseudomonas sp. While there have been no confirmed reports of the biological removal of fluorine atoms from PFAS, the defluorination of monofluorinated compounds by many bacteria has been reported (Huang and Jaffé, 2019). For example, under aerobic conditions, pseudomonads have been isolated which can utilize fluoroacetate as a sole carbon source. In this case, the 
TABLE 2 | Removal technologies of PFAS from the environment.

\begin{tabular}{|c|c|c|c|c|c|}
\hline Technologies & Process & Site & Advantages & Disadvantages & Source \\
\hline Adsorption & $\begin{array}{l}\text { Removal of PFAS compounds via } \\
\text { adsorption to selective materials of } \\
\text { adsorbing potential (e.g., Biochar, } \\
\text { Resin, and modified clays) }\end{array}$ & Ex situ/in situ & $\begin{array}{l}\text { Low operational cost } \\
\text { and uses several } \\
\text { materials which are } \\
\text { commercially available }\end{array}$ & $\begin{array}{l}\text { Ineffective for } \\
\text { short-chain PFAS } \\
\text { removal } \\
\text { Interfere with other } \\
\text { pollutants } \\
\text { May require a large } \\
\text { quantity of the } \\
\text { adsorbent may be } \\
\text { required, which causes } \\
\text { a change in the } \\
\text { land use. }\end{array}$ & Zhang et al., 2011 \\
\hline Filtration & $\begin{array}{l}\text { Uses Reverse osmosis or } \\
\text { Nanofiltration to remove PFAS } \\
\text { compounds }\end{array}$ & Ex-situ & $\begin{array}{l}\text { Effective under a wide } \\
\text { range of } \mathrm{pH}\end{array}$ & $\begin{array}{l}\text { Expensive } \\
\text { PFAS molecular weight } \\
\text { dependant } \\
\text { Creates high } \\
\text { concentration waste }\end{array}$ & Tang et al., 2007 \\
\hline Thermal & $\begin{array}{l}\text { Vaporizing the contaminants through } \\
\text { increasing temperature to about } 600 \\
-1,000^{\circ} \mathrm{C} \text {. }\end{array}$ & Ex situ & $\begin{array}{l}\text { High destruction } \\
\text { potential of the PFAS } \\
\text { compounds }\end{array}$ & $\begin{array}{l}\text { Time-consuming, } \\
\text { high-cost and } \\
\text { energy-intensive } \\
\text { approach. } \\
\text { Disturbs the soil and } \\
\text { the ecosystem. }\end{array}$ & Yamada et al., 2005 \\
\hline $\begin{array}{l}\text { Chemical } \\
\text { oxidation/ } \\
\text { reduction }\end{array}$ & $\begin{array}{l}\text { Using chemical oxidants/reducing } \\
\text { agents for the abiotic breakdown of } \\
\text { contaminants }\end{array}$ & In situ and ex situ & $\begin{array}{l}\text { Potential for PFAS } \\
\text { mineralisation; effective } \\
\text { in PFOA removal }\end{array}$ & $\begin{array}{l}\text { Very expensive as it } \\
\text { requires a large volume } \\
\text { of chemicals and } \\
\text { centralized equipment. } \\
\text { Not applicable to treat } \\
\text { all PFAS compounds. } \\
\text { Short-chain PFAS } \\
\text { could result. } \\
\text { Interferes with } \\
\text { other contaminants. }\end{array}$ & $\begin{array}{l}\text { Yates et al., 2014; } \\
\text { Arvaniti et al., } 2015\end{array}$ \\
\hline Soil washing & $\begin{array}{l}\text { Detaching PFAS from the soil by } \\
\text { washing with water }\end{array}$ & Ex situ & $\begin{array}{l}\text { Requires low } \\
\text { technology } \\
\text { Land reuse could } \\
\text { be possible. }\end{array}$ & $\begin{array}{l}\text { Expensive and } \\
\text { time-consuming. } \\
\text { Contaminated } \\
\text { water results. }\end{array}$ & de Bruecker, 2015 \\
\hline Bioremediation & $\begin{array}{l}\text { Use of biological agents (e.g., } \\
\text { Microorganisms and Plants) to } \\
\text { breakdown or accumulate PFAS } \\
\text { compound }\end{array}$ & In situ and ex situ & $\begin{array}{l}\text { Simple, cost-effective, } \\
\text { and environmentally } \\
\text { safe (Green) approach }\end{array}$ & $\begin{array}{l}\text { Limited evidence that } \\
\text { PFAS can be } \\
\text { degraded. } \\
\text { It could take a long } \\
\text { time due to the slow } \\
\text { biodegradation } \\
\text { of PFAS. }\end{array}$ & Presentato et al., 2020 \\
\hline
\end{tabular}

defluorination occurs through:

$$
\begin{aligned}
\mathrm{FCH}_{2} \mathrm{COO}^{-}+ & \mathrm{OH}^{-}>\mathrm{HOCH}_{2} \mathrm{COO}^{-} \\
+ & \mathrm{F}^{-} \text {, where the oxygen of the } \\
& \text { hydroxyl group is derived from water. }
\end{aligned}
$$

Indigenous bacterial species isolated from PFAS-contaminated environments have shown the ability to remediate PFAS compounds; two strains of Pseudomonas (PS27 and PDMF10) were able to remove 32 and $28 \%$ of PFAS compounds, respectively, within 10 days of incubation under alkanotrophic conditions (Presentato et al., 2020). Further, a decrease of around $32 \%$ in PFAS was also reported during a $96 \mathrm{~h}$ incubation of Pseudomonas parafulva (Yi et al., 2016) along with a 67\% decrease in PFAS concentration over $48 \mathrm{~h}$ incubation of Pseudomonas aeruginosa (Kwon et al., 2014). In another study, Pseudomonas plecoglossicida utilized PFAS as an energy source, producing perfluoroheptanoic acid and releasing fluorine ions as a result (Chetverikov et al., 2017). A recent publication reported that following incubation of the ammonium oxidizing bacterium, Acidimicrobium sp. strain A6 with hydrogen as the sole electron donor for 100 days a $60 \%$ reduction in PFAS concentration was observed (Huang and Jaffé, 2019).

While these studies focussed on relatively small organic compounds that contained fluorine atoms, they may help us to understand how selected microbes may break F-C bonds in PFAS. In these terms, it may be also useful to consider microbial activities known to break $\mathrm{Cl}-\mathrm{C}$ bonds. For 
TABLE 3 | Bacteria reported to be capable of bioaccumulating PFAS.

\begin{tabular}{|c|c|c|c|c|c|c|}
\hline Bacterial sp. & Process & Conditions & $\begin{array}{c}\text { Concentration } \\
\text { removed }(\%)\end{array}$ & $\begin{array}{l}\text { Initial PFAS } \\
\text { concentration }\end{array}$ & $\begin{array}{l}\text { Treatment } \\
\text { time }\end{array}$ & Source \\
\hline $\begin{array}{l}\text { Pseudomonas sp. } \\
\text { strain PS27 }\end{array}$ & Bioaccumulation & Aerobic & 32 & $200 \mathrm{ng} \mathrm{L}^{-1}$ & 10 days & $\begin{array}{l}\text { Presentato } \\
\text { et al., } 2020\end{array}$ \\
\hline $\begin{array}{l}\text { Pseudomonas sp. } \\
\text { strain PDMF10 }\end{array}$ & Bioaccumulation & Aerobic & 28 & $200 \mathrm{ng} \mathrm{L}^{-1}$ & 10 days & $\begin{array}{l}\text { Presentato } \\
\text { et al., } 2020\end{array}$ \\
\hline $\begin{array}{l}\text { Pseudomonas } \\
\text { parafulva }\end{array}$ & Biodegradation & Aerobic & 32 & $500 \mathrm{mg} \mathrm{L}^{-1}$ & $96 \mathrm{~h}$ & Yi et al., 2016 \\
\hline $\begin{array}{l}\text { Pseudomonas } \\
\text { aeruginosa strain } \\
\text { HJ4 }\end{array}$ & Biodegradation & Aerobic & 67 & $\begin{array}{l}1,400-1,800 \\
\mu g L^{-1}\end{array}$ & $48 \mathrm{~h}$ & $\begin{array}{l}\text { Kwon et al., } \\
2014\end{array}$ \\
\hline $\begin{array}{l}\text { Pseudomonas } \\
\text { plecoglossicida } \\
2.4-D\end{array}$ & Biodegradation & Aerobic & 75 & $1 \mathrm{~g} \mathrm{~L}^{-1}$ & 6 days & $\begin{array}{l}\text { Chetverikov } \\
\text { et al., } 2017\end{array}$ \\
\hline $\begin{array}{l}\text { Acidimicrobium } \\
\text { sp. strain A6 }\end{array}$ & $\begin{array}{l}\text { Defluorination/ } \\
\text { biodegradation }\end{array}$ & Anaerobic & 60 & $100 \mathrm{mg} \mathrm{L}^{-1}$ & 100 days & $\begin{array}{l}\text { Huang and } \\
\text { Jaffé, } 2019\end{array}$ \\
\hline $\begin{array}{l}\text { Gordonia sp. } \\
\text { strain NB4-1Y }\end{array}$ & Biodegradation & Sulfur-limiting & 70 & n.d. & 7 days & $\begin{array}{l}\text { Shaw et al., } \\
2019\end{array}$ \\
\hline
\end{tabular}

example, Dehalobacter sp. strain TeCB1 was able to carry out the reductive dechlorination of 1,2,4,5-tetrachlorobenzene to 1,3- and 1,4-dichlorobenzene with 1,2,4-trichlorobenzene being the intermediate daughter product (Alfán-Guzmán et al., 2017). A key enzyme is PceC, and the $C$ subunit of the tetrachloroethene (PCE) reductive dehalogenase is encoded by the conserved pceABCT gene cluster identified in the microbial strain Dehalobacter restrictus PER-K23 (Buttet et al., 2018). Importantly, providing an electron donor can improve reductive dehalogenation catalyzed by specific bacteria (Holliger and Schumacher, 1994). To grow, these microbes utilize organohalide respiration (OHR), which is the energy metabolism of anaerobic bacteria able to use halogenated organic compounds as terminal electron acceptors (Buttet et al., 2018).

In terms of potential enzymes capable of degradading PFAS, reduction could be undertaken by a P450-type enzyme or similar. In organic chemistry F, in F-C bonds, can be replaced by transition metals (Kiplinger et al., 1994), and therefore transition metal-dependent enzymes can release $\mathrm{F}$ from $\mathrm{F}-\mathrm{C}$ bonds (Figure 2). The F in F-C bonds is significantly electronegative, and therefore can promote attraction to transition metal cations. The value of a transition metal in an enzyme reaction is to allow the recycling of its charge state. For example, P450-type enzymes contain a transition iron cation, with activity modified by a heme group for its reaction. Some mixed-function oxidases and horseradish peroxidases have been reported to defluorinate monofluorinated compounds (Goldman and Milne, 1966).

Recently a mode of oxygen-independent defluorination was identified for the complete degradation of para-substituted fluoroaromatics by the denitrifying bacterium Thauera aromatica. This microbe utilizes a class I benzoyl-coenzyme A (BzCoA) reductase (BCR), which catalyzes the ATPdependent defluorination of $4-\mathrm{F}-\mathrm{BzCoA}$ to $\mathrm{BzCoA}$. Other enzymes involved are 1,5-dienoyl-CoA hydratase (DCH) and bifunctional 6-oxo-1-enoyl-CoA hydrolase $(\mathrm{OAH})$. The outcome of the complete degradation of 2-F-benzoate is the production of $\mathrm{HF}$ and $\mathrm{CO}_{2}$ (Tiedt et al., 2016, 2017) (Figure 2).

Both F-1,5-dienoyl-CoA isomers (compounds 2/2*) are hydrated to different F-OH-1-enoyl-CoA isomers (compounds $11 / 11^{*}$ ) by $\mathrm{DCH}$ and $\mathrm{OAH}$, respectively. Unstable 6-F-6-OH-1-enoyl-CoA $\left(11^{*}\right)$ spontaneously decomposes to 6-oxo-1-enoyl-CoA (compound 7) by HFexpulsion. This, in the presence of $\mathrm{OAH}$ becomes immediately hydrated presumably to 2-oxo-6-OH-cyclohexanoyl-CoA (compound 12) before hydrolysis to 3-OH-pimeloylCoA (compound 8). Stable 2-F-6-OH-1-enoyl-CoA (compound 11) can also only be further hydrated by $\mathrm{OAH}$, apparently to the unstable 2-F-2,6-di-OH-cyclohexanoylCoA intermediate, which spontaneously decomposes to compound 12 before ring hydrolysis by OAH. Intermediates illustrated with brackets probably only occur transiently (Tiedt et al., 2017).

\section{Microbial Interaction With PFAS}

Perfluorinated chemicals are chemically very stable and metabolically either completely stable or barely biodegradable so that they can be classified as persistent substances (Von Der Trenck et al., 2018). However, investigations have inferred that limited biotransformation of these chemicals can occur in natural and industrial environments. It is, therefore, important to understand what biotransformation occurs in practice, given the variation in toxicity across the range of potential PFAS products that may be produced due to biotransformation. A further goal is to find organisms that can significantly remove fluorine atoms from these compounds to substantially reduce their toxicity and stability.

It has been demonstrated that fluorinated precursors can be transformed to PFAS, with variable efficiency by a range of biological systems (soil/wastewater; Liu and Avendano, 2013; Lee et al., 2014). Attempts have been made to infer pathways for the biotransformation of fluorinated precursors (D'eon and Mabury, 


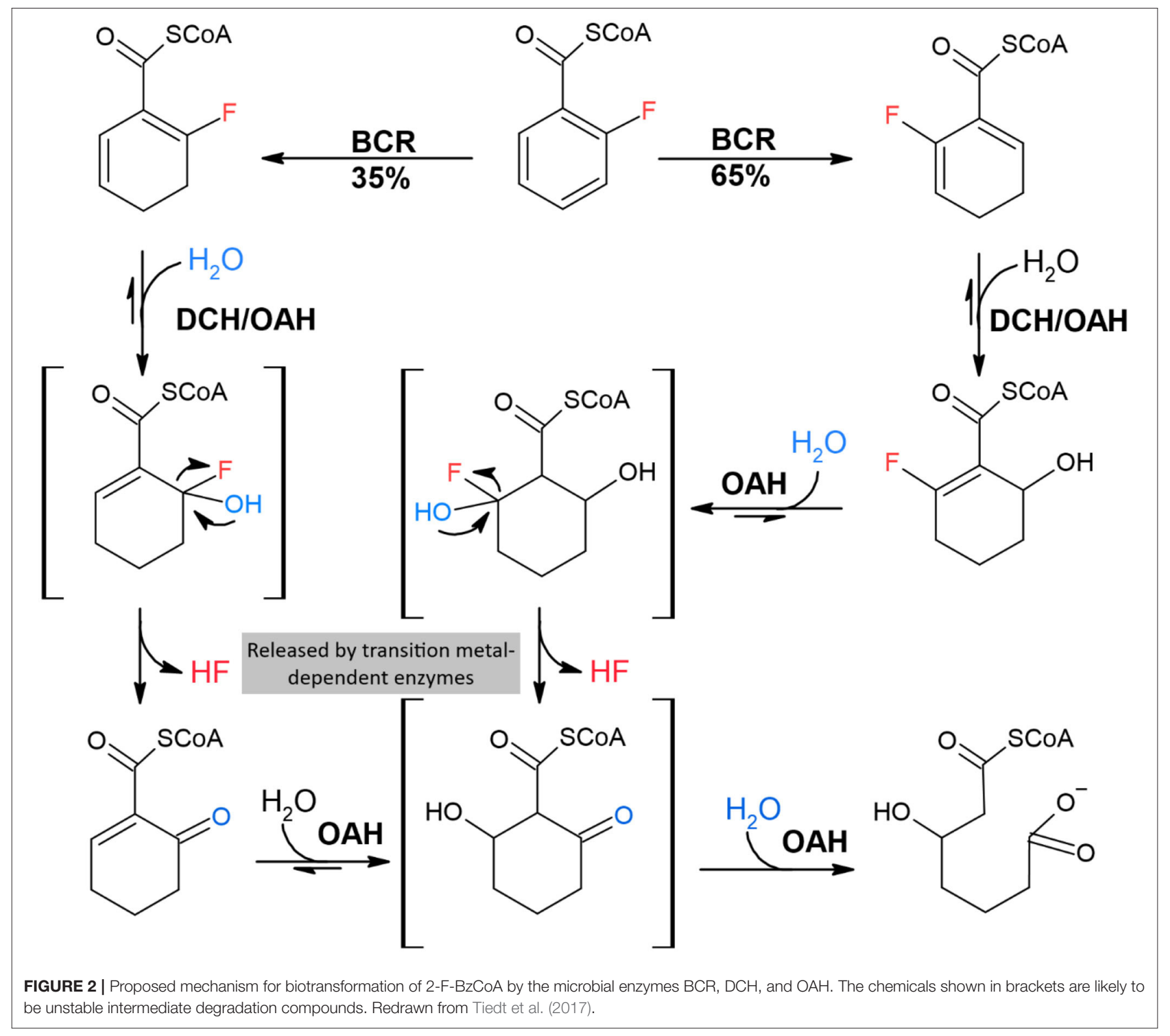

2007; Rhoads et al., 2008; Wang et al., 2009; Liu and Avendano, 2013; Lewis et al., 2016) (Figure 3). However, these tend to be limited to side chains, without significant removal of fluorine atoms. This is unfortunate, in terms of potentially increased toxicity, though may provide a useful basis to further investigate biodegradation of PFAS.

In a further study, two different microbial consortia were isolated from two river sediments in Saitama and Osaka, Japan, known for long term pollution with PFOS and PFOA (Beskoski et al., 2018). Amicrobial chemoorganoheterotrophic consortia which included bacteria, yeast and molds was able to significantly decrease concentrations of PFOS and PFOA between 46-69\% and $16-36 \%$, respectively. However, defluorinated PFOS and PFOA products were not detected, though several metabolites were found only in samples from consortia with PFOS and
PFOA. It was suggested these were associated with unsaturated monofluorinated fatty acids and hydrocarbons with multiple unsaturated bonds or ring structures (Beskoski et al., 2018). Nevertheless, if confirmed, this is problematic as the fluorine is still attached to an organic molecule that could be simply transferred to other organisms through a food web.

While specific biodegrading pathways for some PFAS have been investigated (Liu and Avendano, 2013), for many PFAS, the pathways are unknown. Moreover, the types of enzymes and associated genes involved have not been reported. A degradation pathway for a particular PFAS may be investigated by assessing the intermediate products in a sampling time series. Organisms able to degrade these compounds may optimally be selected from environmental areas that have been polluted with the particular PFAS. This approach has been utilized for developing 


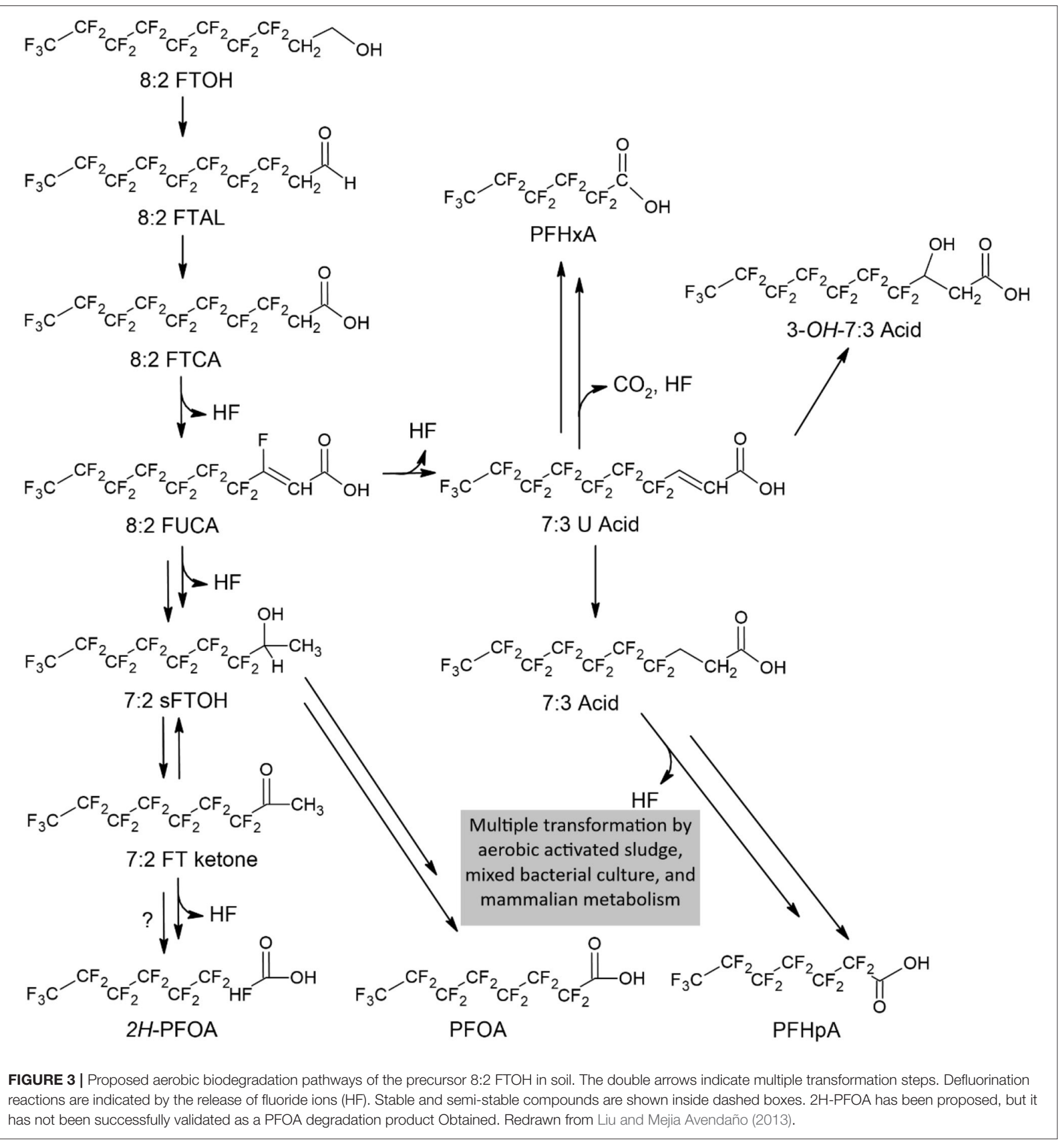

bioremediation of soils polluted with oil products (Moliterni et al., 2012). The types of enzymes involved in biodegradation may be inferred by assessing the intermediate products, followed by a search of the KEGG database (Kanehisa et al., 2018) to confirm the type of enzymes and infer the structural genes that produce these enzymes.
It is also important to understand the biodegrading pathways of PFAS precursors in more detail, to potentially support bioremediation of PFAS and their precursors. It is also useful to recognize that transformations of PFAS may be potentially caused by chemical factors, as well as biological activities. 
While biotransformation of PFAS commonly occurs, high concentrations may reduce biotransformation rates due to chemical toxicity. The impact of PFOA on the activated sludge process has been assessed using a lab-scale sequencing batch reactor, which was continuously exposed to PFOA (Yu et al., 2018). This method used a representative concentration for PFAS $\left(20 \mathrm{mg} \mathrm{L}^{-1}\right)$ to mimic extreme conditions from industrial waste or groundwater from fire-fighting practice sites. The results indicate that PFOA restrained microbial growth which affected dissolved organic carbon removal. Also, continued exposure to PFOA resulted in a significant shift in community structure, leading to the presence of more PFOA-tolerant species (Bacteroidetes, Proteobacteria, and in particular Acidobacteria) (Table 3).

It is important to investigate biodegradation of PFAS under both aerobic and anaerobic conditions and in particular, to assess biotransformation intermediates in a reductive environment (Liu and Avendano, 2013), given the current limited PFAS biodegradation reported in aerobic environments. An oxygenindependent pathway may lead to enhanced degradation (Tiedt et al., 2016, 2017).

\section{Mycoremediation}

To date, research is limited on their ability of fungi to degrade PFAS. This is perhaps surprising given they are known to degrade lignin, one of the most recalcitrant natural compounds along with many toxic natural and xenobiotic compounds including organochlorines [e.g., DDT and DDE, organophosphates, pesticides, including chlorpyrifos and polychlorinated biphenyls (Beaudette et al., 2000) andpolyaromatic hydrocarbons (Moghimi et al., 2017)].

White-rot fungi in particular have displayed relative success in terms of the biotransformation of organic toxicants, including polychlorinated biphenyls, organophosphate pesticides and polycyclic aromatic hydrocarbons (Kaur et al., 2016; Stella et al., 2017; Harry-Asobara and Kamei, 2019). There are very few studies examining their ability to degrade PFAS. Tseng et al. (2014) reported some promising preliminary results looking at the effects of wood-rotting fungus on 6:2 FTOH, using the ligninolytic fungi, Phanerochaete chrysosporium. P. chrysosporium was capable of transforming $50 \%$ of $6: 2 \mathrm{FTOH}$ and $70 \%$ 8:2 FTOH in 28 days. Major metabolites of $6: 2$ FTOH included 5:3 polyfluorinated acid (40\%), 5:2 FTOH (10\%), PFHxA (4\%). In contrast, the non-lignolytic fungus Aspergillus niger was unable to transform 6:2 FTOH over 35 days. while the same study reported that $P$. chrysosporium was capable of transforming 20\% PFOS within 28 days. However, this research was conducted in a laboratory; it remains to be determined whether ligninolytic fungi are capable of degrading PFAS in the environment.

\section{Phytoremediation}

Phytoremediation represents another potential bioremediation approach for PFAS removal from contaminated environments due to the ability of several plants to bioaccumulate PFAS. Although PFAS are not extensively degraded during phytoremediation, bioaccumulation in plants creates a potential route for removal of PFAS from contaminated environments. Phytoremediation has been successfully used for the removal of several environmental contaminants including heavy metals and chlorinated substances (Huff et al., 2020).

Several plants have been used to accumulate PFAS. The wetland species Juncus effuses accumulated $11.4 \%$ of seven PFAS compounds from PFAS-spiked soil (Zhang et al., 2019). Betula pendula and Picea abies were reported to accumulate up to 97 and $94 \mathrm{ng} \mathrm{g}^{-1}$, respectively, during a study at a firefighting training site near Stockholm, Sweden, contaminated with 26 PFAS compounds (Gobelius et al., 2017). The phytoremediation of PFAS contaminated soils using herbaceous and woody plant species has also been reported (Huff et al., 2020). The potential of several plants in a greenhouse study to bioaccumulate 6 PFAS compounds over 14 weeks has been reported (Table 4 ).

\section{Future Prospects and Conclusion}

Using a single bioremediation approach for PFAS may not be successful duet to the process is very slow therefore using a combination of bioremediation techniques to maximize the remediation of PFAS may offer a better approach (Ji et al., 2020). In one study, a combination of phytoremediation and PFAS-degrading bacteria in a constructed wetland was recommended as an effective and environmentally friendly approach that integrates optimum physio-chemical conditions and enhanced microbial degradation. The effectiveness of this "treatment train" approach has previously been reported in removing several emerging contaminants, such as pesticides, pharmaceutical and personal care products (Lv et al., 2016; Liu et al., 2019).

Constructed wetlands consist of three main components which are substrates, plants and microorganisms. The substrate, such as biochar, works as an absorbent of long-chain PFAS as well as media for plant growth and provides surface area for microbial biofilm production (Yang et al., 2018). Plants are another essential component of the constructed wetlands due to their ability to accumulate PFAS in different plant parts, including leaves and roots tissues (Zhang et al., 2019). Plant and substrate disposal, however, remains a great challenge. Thus, thermal treatment could be required for the complete mineralization of adsorbed and bioaccumulated PFAS (Gagliano et al., 2020). Microorganisms are the most important component of the wetland; however, the indigenous microbes have limited ability to biodegrade PFAS. The introduction of microorganisms that can degrade a certain contaminant has been proven to enhance the biodegradation of several emerging contaminants, such as antibiotics and personal care products (Li et al., 2019). Therefore, the introduction of defluorinating microorganisms that can use methane and hydrogen as an electron donor, to the constructed wetlands could enhance the breakdown of the C-F bond and the biodegradation of PFAS compounds (Huang and Jaffé, 2019). However, further investigation is required to assess the effectiveness of this approach (Ji et al., 2020).

Microalgae have shown the ability to remediate several emerging contaminants, including PFAS, through 
TABLE 4 | Bioaccumulation of PFAS compounds by herbaceous plant species [Adapted from Huff et al. (2020)].

\begin{tabular}{|c|c|c|c|c|c|c|c|c|c|c|c|c|}
\hline \multirow[t]{3}{*}{ Plant species } & \multicolumn{12}{|c|}{ Bioaccumulated PFAS compounds } \\
\hline & \multicolumn{2}{|c|}{ PFPeA } & \multicolumn{2}{|c|}{ PFHxA } & \multicolumn{2}{|c|}{ PFOA } & \multicolumn{2}{|c|}{ PFBS } & \multicolumn{2}{|c|}{ PFHxS } & \multicolumn{2}{|c|}{ PFOS } \\
\hline & $\mu \mathbf{g}$ & $\%$ & $\mu \mathbf{g}$ & $\%$ & $\mu \mathrm{g}$ & $\%$ & $\mu \mathbf{g}$ & $\%$ & $\mu \mathbf{g}$ & $\%$ & $\mu \mathbf{g}$ & $\%$ \\
\hline $\begin{array}{l}\text { Amaranthus } \\
\text { tricolor }\end{array}$ & 446 & 30.9 & 153 & 8.1 & 66 & 7.7 & 4 & 0.4 & 1 & 4 & 0 & 0 \\
\hline Brassica juncea & 114 & 11.8 & 72 & 5.7 & 15 & 2.7 & 9 & 1.7 & 8 & 1.6 & 4 & 0.7 \\
\hline Cynodon dactylon & 434 & 22.6 & 427 & 16.9 & 55 & 4.9 & 156 & 14.1 & 51 & 4.8 & 20 & 2 \\
\hline $\begin{array}{l}\text { Equisetum } \\
\text { hyemale }\end{array}$ & 759 & 39.5 & 557 & 22.1 & 36 & 3.2 & 1 & 0.1 & 7 & 0.6 & 4 & 0.4 \\
\hline Festuca rubra & 717 & 37.4 & 652 & 25.9 & 122 & 10.8 & 224 & 20.3 & 141 & 13.2 & 39 & 3.8 \\
\hline Helianthus annuus & 52 & 5.5 & 8 & 0.6 & 4 & 0.8 & 2 & 0.4 & 3 & 0.6 & 1 & 0.2 \\
\hline $\begin{array}{l}\text { Schedonorus } \\
\text { arundinaceus }\end{array}$ & 807 & 42 & 696 & 27.6 & 60 & 5.3 & 262 & 23.8 & 92 & 8.6 & 14 & 1.4 \\
\hline $\begin{array}{l}\text { Trifolium } \\
\text { incarnatum }\end{array}$ & 29 & 3.1 & 11 & 0.8 & 50 & 8.9 & 13 & 2.3 & 10 & 1.9 & 1 & 0.2 \\
\hline
\end{tabular}

bioaccumulation, biodegradation and bio-adsorption. However, to date, most of the studies that have been conducted on microalgal-bioremediation are laboratorybased experiments under control conditions and the transition to field applications remains a challenge. Therefore, further research is required to employ microalgal species to bioremediate PFAS, which demonstrate increased biodegradation potential (Sutherland and Ralph, 2019).

The other role that microalgae may play in remediating emerging contaminants is enhancing bacterial biodegradation. Microalgal cells provide oxygen, an essential electron acceptor, via photosynthesis for the aerobic bacterial species, which in turn, produces $\mathrm{CO}_{2}$ which is required for microalgal photosynthesis (Sutherland et al., 2015). Microalgae release dissolved organic matter (DOM) which can biostimulate bacterial degradation of the contaminants although the mechanism for the bacterial biostimulation is not fully understood. Thus, investigating the relationship between microalgae and bacteria and the optimum physico-chemical conditions are crucial steps to enhance the bioremediation process (Sutherland and Ralph, 2019).

Both fungal and bacterial strains have been isolated that are capable of degrading PFAS; however, degradation is slow and incomplete. In addition, information regarding the biodegradation and bioaccumulation of PFAS using bacteria and fungi is limited. Thus, more research needs to be undertaken. This is a crucial limitation to the development of any robust bioremediation strategy. However, with the current array of approaches and tools available to microbial ecologists, including stable isotope probing, metagenomics, transcriptomics and metabolomics, the identification of degradative pathways and the subsequent harnessing of PFAS-exposed microbial communities for remediation remains a possibility and further work needs to be performed to underpin the degradation process. Further studies could lead to an understanding of the pathways of degradation, by comparison to proposed published pathways in soil, for example (Liu and Avendano, 2013). In turn, the possible enzymes involved in degrading PFAS can be inferred by comparing the structures of PFAS in the proposed pathways. It would also be of value to list the potential genes in key bacteria that express the types of enzymes involved in degrading It would be useful to find and characterize microbes in contaminated soils that are capable of degrading PFAS and to quantify bioaccumulation and biomagnification of PFAS in trophic levels of marine ecosystems, in particular, to improve the assessment of health risks in human consumption of seafood contaminated by PFAS. Stable isotope probing (SIP) has been an extremely useful tool to link microbial identity to function; this technique has been used to elucidate the microbes responsible for the degradation of a variety of xenobiotics (Dumont and Murrell, 2005). The technique can be performed with DNA-SIP (Uhlík et al., 2009) or RNA-SIP which has been used during the degradation of benzene (Aburto, 2007; Aburto and Ball, 2009) and naphthalene (Huang et al., 2009) in groundwater, phenol in a bioreactor (Manefield et al., 2002), phenol in sludge (Sueoka et al., 2009) and tetrachloroethene in river sediments (Kittelmann and Friedrich, 2008) among other types of studies involving trophic interactions, biogeochemical processes or ecosystem functioning (Gutierrez-Zamora and Manefield, 2010). More recently it has been used to identify pesticide degraders (Jiang et al., 2018) and 1-4 dioxane degraders (Aoyagi et al., 2018). Therefore, SIP is a powerful technique that can also be combined with metagenomics (Vo et al., 2007) and transcriptomics (Lueders et al., 2016) and could also aid during the bioremediation of PFAS.

Metagenomics is a valuable tool that has been used recently to assess the stress of polyfluorinated alkyl substances on the microbial community (Cai et al., 2020) as well as their dynamics and structure (Zhang et al., 2020) in different environments such as soil and freshwater ponds. It is also one of the tools of 
synthetic biology (synbio) which has been recently proposed to help in the bioremediation of xenobiotics, among them PFAS (Rylott and Bruce, 2020). Systems biology and protein design will also be critical tools for synbio, that in the future should allow the synthesis of proteins by reprogramming the genetic code and aid in the remediation of the persistent contaminants (Rylott and Bruce, 2020).

\section{REFERENCES}

Aburto, A. (2007). Microbial diversity and factors affecting benzene degradation in a benzene-contaminated aquifer. $\mathrm{PhD}$ thesis, University of Essex, Colchester, United Kingdom.

Aburto, A., and Ball, A. S. (2009). Bacterial population dynamics and separation of active degraders by stable isotope probing during benzene degradation in a BTEX-impacted aquifer. Rev. Int. Contam. Ambient. 25, 147-156.

Adetutu, E. M., Gundry, T. D., Patil, S. S., Golneshin, A., Adigun, J., Bhaskarla, V., et al. (2015). Exploiting the intrinsic microbial degradative potential for fieldbased in situ dechlorination of trichloroethene contaminated groundwater. J. Hazard. Mater. 300, 48-57. doi: 10.1016/j.jhazmat.2015.06.055

Alfán-Guzmán, R., Ertan, H., Manefield, M., and Lee, M. (2017). Isolation and characterization of Dehalobacter sp. strain TeCB1 including identification of TcbA: a novel tetra- and trichlorobenzene reductive dehalogenase. Front. Microbiol. 8:558. doi: 10.3389/fmicb.2017.00558

Allred, B. M., Lang, J. R., Barlaz, M. A., and Field, J. A. (2015). Physical and biological release of poly-and perfluoroalkyl substances (PFAS) from municipal solid waste in anaerobic model landfill reactors. Environ. Sci. Technol. 49, 7648-7656. doi: 10.1021/acs.est.5b01040

Aoyagi, T., Morishita, F., Sugiyama, Y., Ichikawa, D., Mayumi, D., Kikuchi, Y., et al. (2018). Identification of active and taxonomically diverse 1,4-dioxane degraders in a full-scale activated sludge system by high-sensitivity stable isotope probing. ISME J. 12, 2376-2388. doi: 10.1038/s41396-018-0201-2

Arvaniti, O. S., Hwang, Y., Andersen, H. R., Stasinakis, A. S., Thomaidis, N. S., and Aloupi, M. (2015). Reductive degradation of perfluorinated compounds in water using Mg-aminoclay coated nanoscale zero valent iron. Chem. Eng. J. 262, 133-139. doi: 10.1016/j.cej.2014.09.079

Backe, W. J., Day, T. C., and Field, J. A. (2013). Zwitterionic, cationic, and anionic fluorinated chemicals in aqueous film forming foam formulations and groundwater from US military bases by nonaqueous large-volume injection HPLC-MS/MS. Environ. Sci. Technol. 47, 5226-5234. doi: 10.1021/es30 34999

Beaudette, L., Ward, O., Pickard, M., and Fedorak, P. (2000). Low surfactant concentration increases fungal mineralization of a polychlorinated biphenyl congener but has no effect on overall metabolism. Lett. Appl. Microbiol. 30, 155-160. doi: 10.1046/j.1472-765x.2000.00700.x

Beskoski, V. P., Yamamoto, A., Nakano, T., Yamamoto, K., Matsumura, C., Motegi, M., et al. (2018). Defluorination of perfluoroalkyl acids is followed by production of monofluorinated fatty acids. Sci. Total Environ. 636, 355-359. doi: 10.1016/j.scitotenv.2018.04.243

Blaine, A. C., Rich, C. D., Sedlacko, E. M., Hundal, L. S., Kumar, K., Lau, C., et al. (2014). Perfluoroalkyl acid distribution in various plant compartments of edible crops grown in biosolids-amended soils. Environ. Sci. Technol. 48, 7858-7865. doi: 10.1021/es500016s

Buck, R. C., Franklin, J., Berger, U., Conder, J. M., Cousins, I. T., De Voogt, P., et al. (2011). Perfluoroalkyl and polyfluoroalkyl substances in the environment: terminology, classification, and origins. Integr. Environ. Assess. Manag. 7, 513-541. doi: 10.1002/ieam.258

Buttet, G. F., Willemin, M. S., Hamelin, R., Rupakula, A., and Maillard, J. (2018). The membrane-bound $\mathrm{C}$ subunit of reductive dehalogenases: topology analysis and reconstitution of the FMN-binding domain of PceC. Front. Microbiol. 9:755. doi: 10.3389/fmicb.2018.00755

Cabrerizo, A., Muir, D. C., de Silva, A. O., Wang, X., Lamoureux, S. F., and Lafreni $\tilde{A}$ ?Re, M. J. (2018). Legacy and emerging persistent organic pollutants (POPs) in terrestrial compartments in the high Arctic: sorption and secondary sources. Environ. Sci. Technol. 52, 14187-14197. doi: 10.1021/acs.est.8b 05011

\section{AUTHOR CONTRIBUTIONS}

ES, DR, and LK wrote the manuscript. DT and AA-M contributed to the collection of literature and summarization. ES and AB guided throughout the preparation of the paper, proofreading the paper, and revised it. All authors fully agreed for publication of the paper.

Cai, M., Zhao, Z., Yin, Z., Ahrens, L., Huang, P., Cai, M., et al. (2012). Occurrence of perfluoroalkyl compounds in surface waters from the North Pacific to the Arctic Ocean. Environ. Sci. Technol. 46, 661-668. doi: 10.1021/es2026278

Cai, Y., Chen, H., Yuan, R., Wang, F., Chen, Z., and Zhou, B. (2020). Metagenomic analysis of soil microbial community under PFOA and PFOS stress. Environ. Res. 188:109838. doi: 10.1016/j.envres.2020.109838

Chetverikov, S. P., Sharipov, D. A., Korshunova, T. Y., and Loginov, O. (2017). Degradation of perfluorooctanyl sulfonate by strain Pseudomonas plecoglossicida 2.4-D. Appl. Biochem. Microbiol. 53, 533-538. doi: 10.1134/S0003683817050027

Darrow, L. A., Stein, C. R., and Steenland, K. (2013). Serum perfluorooctanoic acid and perfluorooctane sulfonate concentrations in relation to birth outcomes in the Mid-Ohio Valley, 2005-2010. Environ. Health Perspect. 121, 1207-1213. doi: 10.1289/ehp.1206372

Dauchy, X., Boiteux, V., Colin, A., Bach, C., Rosin, C., and Munoz, J.-F. (2019). Poly-and perfluoroalkyl substances in runoff water and wastewater sampled at a firefighter training area. Arch. Environ. Contam. Toxicol. 76, 206-215. doi: 10.1007/s00244-018-0585-z

de Bruecker, T. (2015). Status report PFOS remediation. DEC Environ. Solutions 12.

D'eon, J. C., and Mabury, S. A. (2007). Production of perfluorinated carboxylic acids (PFCAs) from the biotransformation of polyfluoroalkyl phosphate surfactants (PAPS): exploring routes of human contamination. Environ. Sci. Technol. 41, 4799-4805. doi: 10.1021/es070126x

Dumont, M. G., and Murrell, J. C. (2005). Stable isotope probinglinking microbial identity to function. Nat. Rev. Microbiol. 3, 499-504. doi: 10.1038/nrmicro1162

Eriksson, U., Haglund, P., and Karrman, A. (2017). Contribution of precursor compounds to the release of per- and polyfluoroalkyl substances (PFAS) from waste water treatment plants (WWTPs). J. Environ. Sci. 61, 80-90. doi: 10.1016/j.jes.2017.05.004

Eriksson, U., and Karrman, A. (2015). World-wide indoor exposure to polyfluoroalkyl phosphate esters (PAPs) and other PFAS in household dust. Environ. Sci. Technol. 49, 14503-14511. doi: 10.1021/acs.est.5b00679

Gagliano, E., Sgroi, M., Falciglia, P. P., Vagliasindi, F. G., and Roccaro, P. (2020). Removal of poly-and perfluoroalkyl substances (PFAS) from water by adsorption: role of PFAS chain length, effect of organic matter and challenges in adsorbent regeneration. Water Res. 171:115381. doi: 10.1016/j.watres.2019.115381

Gallen, C., Eaglesham, G., Drage, D., Nguyen, T. H., and Mueller, J. (2018). A mass estimate of perfluoroalkyl substance (PFAS) release from Australian wastewater treatment plants. Chemosphere 208, 975-983. doi: 10.1016/j.chemosphere.2018.06.024

Ghisi, R., Vamerali, T., and Manzetti, S. (2019). Accumulation of perfluorinated alkyl substances (PFAS) in agricultural plants: a review. Environ. Res. 169, 326-341. doi: 10.1016/j.envres.2018.10.023

Giesy, J. P., Naile, J. E., Khim, J. S., Jones, P. D., and Newsted, J. L. (2010). "Aquatic toxicology of perfluorinated chemicals," in Reviews of Environmental Contamination and Toxicology? (New York, NY: Springer), 1-52. . doi: 10.1007/978-1-4419-1157-5_1

Giesy, J., and Kannan, K. (2002). Perfluorochemical surfactants in the environment. Environ. Sci. Technol. 36, 146A-152A. doi: 10.1021/es022253t

Giesy, J. P., and Kannan, K. (2001). Global distribution of perfluorooctane sulfonate in wildlife. Environ. Sci. Technol. 35, 1339-1342. doi: $10.1021 /$ es001834k

Gobelius, L., Lewis, J., and Ahrens, L. (2017). Plant uptake of per- and polyfluoroalkyl substances at a contaminated fire training facility to evaluate the phytoremediation potential of various plant species. Environ. Sci. Technol. 51, 12602-12610. doi: 10.1021/acs.est.7b02926 
Goldman, P., and Milne, G. W. A. (1966). Carbon-fluorine bond cleavage. II. Studies on the mechanism of the defluorination of fluoroacetate. J. Biol. Chem. 241, 5557-5559.

Gutierrez-Zamora, M.-L., and Manefield, M. (2010). An appraisal of methods for linking environmental processes to specific microbial taxa. Rev. Environ. Sci. Biotechnol. 9, 153-185. doi: 10.1007/s11157-010-9205-8

Hamid, H., Li, L. Y., and Grace, J. R. (2018). Review of the fate and transformation of per-and polyfluoroalkyl substances (PFAS) in landfills. Environ. Pollut. 235, 74-84. doi: 10.1016/j.envpol.2017.12.030

Harding-Marjanovic, K. C., Houtz, E. F., Yi, S., Field, J. A., Sedlak, D. L., and Alvarez-Cohen, L. (2015). Aerobic biotransformation of fluorotelomer thioether amido sulfonate (Lodyne) in AFFF-amended microcosms. Environ. Sci. Technol. 49, 7666-7674. doi: 10.1021/acs.est.5b01219

Harry-Asobara, J. L., and Kamei, I. (2019). Growth management of white-rot fungus Phlebia brevispora improved degradation of highmolecular-weight polycyclic aromatic hydrocarbons. Biotech 9:403. doi: 10.1007/s13205-019-1932-0

Hepburn, E., Madden, C., Szabo, D., Coggan, T. L., Clarke, B., and Currell, M. (2019). Contamination of groundwater with per-and polyfluoroalkyl substances (PFAS) from legacy landfills in an urban re-development precinct. Environ. Pollut. 248, 101-113. doi: 10.1016/j.envpol.2019.02.018

Higgins, C. P., and Luthy, R. G. (2006). Sorption of perfluorinated surfactants on sediments. Environ. Sci. Technol. 40, 7251-7256. doi: 10.1021/es061000n

Holliger, C., and Schumacher, W. (1994). Reductive dehalogenation as a respiratory process. Antonie Van Leeuwenhoek 66, 239-246. doi: $10.1007 / \mathrm{BF} 00871642$

Hu, X. C., Andrews, D. Q., Lindstrom, A. B., Bruton, T. A., Schaider, L. A., Grandjean, P., et al. (2016). Detection of poly-and perfluoroalkyl substances (PFAS) in US drinking water linked to industrial sites, military fire training areas, and wastewater treatment plants. Environ. Sci. Technol. Lett. 3, 344-350. doi: 10.1021/acs.estlett.6b00260

Huang, S., and Jaffé, P. R. (2019). Defluorination of Perfluorooctanoic acid (PFOA) and perfluorooctane sulfonate (PFOS) by Acidimicrobium sp. strain A6. Environ. Sci. Technol. 53, 11410-11419. doi: 10.1021/acs.est.9b04047

Huang, W. E., Ferguson, A., Singer, A. C., Lawson, K., Thompson, I. P., Kalin, R. M., et al. (2009). Resolving genetic functions within microbial populations: in situ analyses using rRNA and mRNA stable isotope probing coupled with single-cell raman-fluorescence in situ hybridization. Appl. Environ. Microbiol. 75, 234-241. doi: 10.1128/AEM.01861-08

Huff, D. K., Morris, L. A., Sutter, L., Costanza, J., and Pennell, K. D. (2020). Accumulation of six PFAS compounds by woody and herbaceous plants: potential for phytoextraction. Int. J. Phytoremediation 22, 1538-1550. doi: 10.1080/15226514.2020.1786004

Ji, B., Kang, P., Wei, T., and Zhao, Y. (2020). Challenges of aqueous per- and polyfluoroalkyl substances (PFAS) and their foreseeable removal strategies. Chemosphere 250:126316. doi: 10.1016/j.chemosphere.2020.126316

Jiang, B., Jin, N., Xing, Y., Su, Y., and Zhang, D. (2018). Unraveling uncultivable pesticide degraders via stable isotope probing (SIP). Crit. Rev. Biotechnol. 38, 1025-1048. doi: 10.1080/07388551.2018.1427697

Kanehisa, M., Sato, Y., Furumichi, M., Morishima, K., and Tanabe, M. (2018). New approach for understanding genome variations in KEGG. Nucleic Acids Res. 47, D590-D595. doi: 10.1093/nar/gky962

Kaur, H., Kapoor, S., and Kaur, G. (2016). Application of ligninolytic potentials of a white-rot fungus Ganoderma lucidum for degradation of lindane. Environ. Monit. Assess 188:588. doi: 10.1007/s10661-016-5606-7

Khudur, L. S., Shahsavari, E., Webster, G. T., Nugegoda, D., and Ball, A. S. (2019). The impact of lead co-contamination on ecotoxicity and the bacterial community during the bioremediation of total petroleum hydrocarboncontaminated soils. Environ. Pollut. 253, 939-948. doi: 10.1016/j.envpol.2019.0 7.107

Kim, S., Khim, J., Lee, K., Giesy, J., Kannan, K., and Koh, D. (2007). "Emission, contamination and exposure, fate and transport, and national management strategy of persistent organic pollutants in South Korea," in Persistent Organic Pollutants in Asia: Sources, Distributions, Transport and Fate, eds A. Li, S. Tanabe, G. Jiang, J. P. Giesy, and P. K.S. Lam. (Amsterdam: Elsevier), 31-157. doi: 10.1016/S1474-8177(07)07 $002-7$
Kiplinger, J. L., Richmond, T. G., and Osterbergt, C. E. (1994). Activation of carbon-fluorine bonds by metal complexes. Chem. Rev. 94, 373-431. doi: 10.1021/cr00026a005

Kittelmann, S., and Friedrich, M. W. (2008). Identification of novel perchloroethene-respiring microorganisms in anoxic river sediment by RNA-based stable isotope probing. Environ. Microbiol. 10, 31-46. doi: 10.1111/j.1462-2920.2007.01427.x

Kucharzyk, K. H., Darlington, R., Benotti, M., Deeb, R., and Hawley, E. (2017). Novel treatment technologies for PFAS compounds: a critical review. J. Environ. Manage 204, 757-764. doi: 10.1016/j.jenvman.2017.08.016

Kwon, B. G., Lim, H.-J., Na, S.-H., Choi, B.-I., Shin, D.-S., and Chung, S.-Y. (2014). Biodegradation of perfluorooctanesulfonate (PFOS) as an emerging contaminant. Chemosphere 109, 221-225. doi: 10.1016/j.chemosphere.2014.01.072

Lauritzen, H. B., Larose, T. L., Oien, T., Odland, J. O., Van De Bor, M., Jacobsen, G. W., et al. (2016). Factors associated with maternal serum levels of perfluoroalkyl substances and organochlorines: a descriptive study of parous women in Norway and Sweden. PLoS ONE 11:e0166127. doi: 10.1371/journal.pone.0166127

Lee, H., Tevlin, A. G., Mabury, S. A., and Mabury, S. A. (2014). Fate of polyfluoroalkyl phosphate diesters and their metabolites in biosolids-applied soil: biodegradation and plant uptake in greenhouse and field experiments. Environ. Sci. Technol. 48, 340-349. doi: 10.1021/es403949z

Lewis, M., Kim, M. H., Liu, E. J., Wang, N., and Chu, K. H. (2016). Biotransformation of 6:2 polyfluoroalkyl phosphates (6:2 PAPs): effects of degradative bacteria and co-substrates. J. Hazard. Mater. 320, 479-486. doi: 10.1016/j.jhazmat.2016.08.036

Li, M., Sun, F., Shang, W., Zhang, X., Dong, W., Liu, T., et al. (2019). Theoretical studies of perfluorochemicals (PFCs) adsorption mechanism on the carbonaceous surface. Chemosphere 235, 606-615. doi: 10.1016/j.chemosphere.2019.06.191

Li, Y., Oliver, D. P., and Kookana, R. S. (2018). A critical analysis of published data to discern the role of soil and sediment properties in determining sorption of per and polyfluoroalkyl substances (PFAS). Sci. Total Environ. 628, 110-120. doi: 10.1016/j.scitotenv.2018.01.167

Lindstrom, A. B., Strynar, M. J., and Libelo, E. L. (2011). Polyfluorinated Compounds: Past, Present, and Future. Environ. Sci. Technol. 45, 7954-7961. doi: 10.1021/es2011622

Liu, J., and Avendano, S. M. (2013). Microbial degradation of polyfluoroalkyl chemicals in the environment: a review. Environ. Int. 61, 98-114. doi: 10.1016/j.envint.2013.08.022

Liu, J., and Mejia Avendaño, S. (2013). Microbial degradation of polyfluoroalkyl chemicals in the environment: a review. Environ. Int. 61, 98-114.

Liu, X., Guo, X., Liu, Y., Lu, S., Xi, B., Zhang, J., et al. (2019). A review on removing antibiotics and antibiotic resistance genes from wastewater by constructed wetlands: performance and microbial response. Environ. Pollut. 254:112996. doi: 10.1016/j.envpol.2019.112996

Lu, G.-H., Jiao, X.-C., Piao, H.-T., Wang, X.-C., Chen, S., Tan, K.-Y., et al. (2018). The extent of the impact of a fluorochemical industrial park in eastern China on adjacent rural areas. Arch. Environ. Contam. Toxicol. 74, 484-491. doi: 10.1007/s00244-017-0458-x

Lueders, T., Dumont, M. G., Bradford, L., and Manefield, M. (2016). RNA-stable isotope probing: from carbon flow within key microbiota to targeted transcriptomes. Curr. Opin. Biotechnol. 41, 83-89. doi: 10.1016/j.copbio.2016.05.001

Lv, T., Zhang, Y., Zhang, L., Carvalho, P. N., Arias, C. A., and Brix, H. (2016). Removal of the pesticides imazalil and tebuconazole in saturated constructed wetland mesocosms. Water Res. 91, 126-136. doi: 10.1016/j.watres.2016.01.007

Mahinroosta, R., and Senevirathna, L. (2020). A review of the emerging treatment technologies for PFAS contaminated soils. J. Environ. Manage 255:109896. doi: 10.1016/j.jenvman.2019.109896

Manefield, M., Whiteley, A. S., Griffiths, R. I., and Bailey, M. J. (2002). RNA stable isotope probing, a novel means of linking microbial community function to Phylogeny. Appl. Environ. Microbiol. 68, 5367-5373. doi: 10.1128/AEM.68.11.5367-5373.2002

Moghimi, H., Heidary Tabar, R., and Hamedi, J. (2017). Assessing the biodegradation of polycyclic aromatic hydrocarbons and laccase production by 
new fungus Trematophoma sp. UTMC 5003. World J. Microbiol. Biotechnol. 33:136. doi: 10.1007/s11274-017-2304-8

Moliterni, E., Jiménez-Tusset, R. G., Villar Rayo, M., Rodriguez, L., Fernández, F. J., and Villaseñor, J. (2012). Kinetics of biodegradation of diesel fuel by enriched microbial consortia from polluted soils. Int. J. Environ. Sci. Technol. 9, 749-758. doi: 10.1007/s13762-012-0071-5

Mora, A. M., Oken, E., Rifas-Shiman, S. L., Webster, T. F., Gillman, M. W., Calafat, A. M., et al. (2017). Prenatal exposure to perfluoroalkyl substances and adiposity in early and mid-childhood. Environ. Health Perspect. 125, 467-473. doi: 10.1289/EHP246

Nakayama, S. F., Yoshikane, M., Onoda, Y., Nishihama, Y., Iwai-Shimada, M., Takagi, M., et al. (2019). Worldwide trends in tracing poly-and perfluoroalkyl substances (PFAS) in the environment. TrAC Trends Anal. Chem. 121:115410. doi: 10.1016/j.trac.2019.02.011

Parsons, J. R., Sáez, M., Dolfing, J., and De Voogt, P. (2008). Biodegradation of perfluorinated compounds. Rev. Environ. Contamin. Toxicol. 196, 53-71. doi: 10.1007/978-0-387-78444-1_2

Pérez, F., Nadal, M., Navarro-Ortega, A., Fàbrega, F., Domingo, J. L., Barceló, D., et al. (2013). Accumulation of perfluoroalkyl substances in human tissues. Environ. Int. 59, 354-362. doi: 10.1016/j.envint.2013.06.004

Presentato, A., Lampis, S., Vantini, A., Manea, F., Daprà, F., Zuccoli, S., et al. (2020). On the Ability of perfluorohexane sulfonate (PFHxS) bioaccumulation by two Pseudomonas sp. strains isolated from PFAS-contaminated environmental matrices. Microorganisms 8:92. doi: 10.3390/microorganisms8010092

Rahman, M. F., Peldszus, S., and Anderson, W. B. (2014). Behaviour and fate of perfluoroalkyl and polyfluoroalkyl substances (PFAS) in drinking water treatment: a review. Water Res. 50, 318-340. doi: 10.1016/j.watres.2013.10.045

Rhoads, K. R., Janssen, E. M.-L., Luthy, R. G., and Criddle, C. S. (2008). Aerobic Biotransformation and Fate of N-Ethyl perfluorooctane sulfonamidoethanol (N-EtFOSE) in activated sludge. Environ. Sci. Technol. 42, 2873-2878. doi: $10.1021 /$ es702866c

Rylott, E. L., and Bruce, N. C. (2020). How synthetic biology can help bioremediation. Curr. Opin. Chem. Biol. 58, 86-95. doi: 10.1016/j.cbpa.2020.07.004

Schaider, L. A., Balan, S. A., Blum, A., Andrews, D. Q., Strynar, M. J., Dickinson, M. E., et al. (2017). Fluorinated compounds in U.S. fast food packaging. Environ. Sci. Technol. Lett. 4, 105-111. doi: 10.1021/acs.estlett.6b00435

Seo, S.-H., Son, M.-H., Choi, S.-D., Lee, D.-H., and Chang, Y.-S. (2018). Influence of exposure to perfluoroalkyl substances (PFAS) on the Korean general population: 10-years trend and health effects. Environ. Int. 113, 149-161. doi: 10.1016/j.envint.2018.01.025

Shahsavari, E., Schwarz, A., Aburto-Medina, A., and Ball, A. S. (2019). Biological degradation of polycyclic aromatic compounds (PAHs) in soil: a current perspective. Curr. Pollut. Rep. 5, 84-92. doi: 10.1007/s40726-019-00113-8

Shaw, D. M. J., Munoz, G., Bottos, E. M., Duy, S. V., Sauvé, S., Liu, J., et al. (2019). Degradation and defluorination of 6:2 fluorotelomer sulfonamidoalkyl betaine and 6:2 fluorotelomer sulfonate by Gordonia sp. strain NB4$1 Y$ under sulfur-limiting conditions. Sci. Total Environ. 647, 690-698. doi: 10.1016/j.scitotenv.2018.08.012

Shi, Y., Vestergren, R., Xu, L., Song, X., Niu, X., Zhang, C., et al. (2015). Characterizing direct emissions of perfluoroalkyl substances from ongoing fluoropolymer production sources: a spatial trend study of Xiaoqing River, China. Environ. Pollut. 206, 104-112. doi: 10.1016/j.envpol.2015.06.035

Sorengard, M., Kleja, D. B., and Ahrens, L. (2019). Stabilization of perand polyfluoroalkyl substances (PFAS) with colloidal activated carbon (PlumeStop ${ }^{\circledR}$ ) as a function of soil clay and organic matter content. J. Environ. Manage 249:109345. doi: 10.1016/j.jenvman.2019.109345

Stahl, T., Heyn, J., Thiele, H., Hüther, J., Failing, K., Georgii, S., et al. (2009). Carryover of perfluorooctanoic acid (PFOA) and perfluorooctane sulfonate (PFOS) from soil to plants. Arch. Environ. Contam. Toxicol. 57, 289-298. doi: 10.1007/s00244-008-9272-9

Starling, A. P., Adgate, J. L., Hamman, R. F., Kechris, K., Calafat, A. M., Ye, X., et al. (2017). Perfluoroalkyl substances during pregnancy and offspring weight and adiposity at birth: examining mediation by maternal fasting glucose in the healthy start study. Environ. Health Perspect. 125:067016. doi: 10.1289/EHP641

Steenland, K., Zhao, L., Winquist, A., and Parks, C. (2013). Ulcerative colitis and perfluorooctanoic acid (PFOA) in a highly exposed population of community residents and workers in the mid-Ohio valley. Environ. Health Perspect. 121, 900-905. doi: 10.1289/ehp.1206449

Stella, T., Covino, S., Cvančarová, M., Filipová, A., Petruccioli, M., D’annibale, A., et al. (2017). Bioremediation of long-term PCB-contaminated soil by white-rot fungi. J. Hazard. Mater. 324, 701-710. doi: 10.1016/j.jhazmat.2016.11.044

Sueoka, K., Satoh, H., Onuki, M., and Mino, T. (2009). Microorganisms involved in anaerobic phenol degradation in the treatment of synthetic coke-oven wastewater detected by RNA stable-isotope probing. FEMS Microbiol. Lett. 291, 169-174. doi: 10.1111/j.1574-6968.2008.01448.x

Sunderland, E. M., Hu, X. C., Dassuncao, C., Tokranov, A. K., Wagner, C. C., and Allen, J. G. (2019). A review of the pathways of human exposure to poly- and perfluoroalkyl substances (PFAS) and present understanding of health effects. J. Expo. Sci. Environ. Epidemiol. 29, 131-147. doi: 10.1038/s41370-018-0094-1

Sutherland, D. L., Howard-Williams, C., Turnbull, M. H., Broady, P. A., and Craggs, R. J. (2015). Enhancing microalgal photosynthesis and productivity in wastewater treatment high rate algal ponds for biofuel production. Bioresour. Technol. 184, 222-229. doi: 10.1016/j.biortech.2014.10.074

Sutherland, D. L., and Ralph, P. J. (2019). Microalgal bioremediation of emerging contaminants-opportunities and challenges. Water Res. 164:114921. doi: 10.1016/j.watres.2019.114921

Tang, C. Y., Fu, Q. S., Criddle, C. S., and Leckie, J. O. (2007). Effect of flux (transmembrane pressure) and membrane properties on fouling and rejection of reverse osmosis and nanofiltration membranes treating perfluorooctane sulfonate containing wastewater. Environ. Sci. Technol. 41, 2008-2014. doi: $10.1021 / \mathrm{es} 062052 \mathrm{f}$

Tao, L., Kannan, K., Wong, C. M., Arcaro, K. F., and Butenhoff, J. L. (2008a). Perfluorinated compounds in human milk from Massachusetts, USA. Environ. Sci. Technol. 42, 3096-3101. doi: 10.1021/es702789k

Tao, L., Ma, J., Kunisue, T., Libelo, E. L., Tanabe, S., and Kannan, K. (2008b). Perfluorinated compounds in human breast milk from several Asian countries, and in infant formula and dairy milk from the United States. Environ. Sci. Technol. 42, 8597-8602. doi: 10.1021/es801875v

Teaf, C. M., Garber, M. M., Covert, D. J., and Tuovila, B. J. (2019). Perfluorooctanoic acid (PFOA): environmental sources, chemistry, toxicology, and potential risks. Soil Sediment Contam. 28, 258-273. doi: 10.1080/15320383.2018.1562420

Tiedt, O., Mergelsberg, M., Boll, K., Muller, M., Adrian, L., Jehmlich, N., et al. (2016). ATP-dependent C-F bond cleavage allows the complete degradation of 4-fluoroaromatics without oxygen. MBio 7, e00990-e00916. doi: $10.1128 / \mathrm{mBio} .00990-16$

Tiedt, O., Mergelsberg, M., Eisenreich, W., and Boll, M. (2017). Promiscuous defluorinating Enoyl-CoA hydratases/hydrolases allow for complete anaerobic degradation of 2-fluorobenzoate. Front. Microbiol. 8:2579. doi: $10.3389 /$ fmicb. 2017.02579

Trudel, D., Horowitz, L., Wormuth, M., Scheringer, M., Cousins, I. T., and Hungerbuhler, K. (2008). Estimating consumer exposure to PFOS and PFOA. Risk Anal. 28, 251-269. doi: 10.1111/j.1539-6924.2008.01017.x

Tseng, N., Wang, N., Szostek, B., and Mahendra, S. (2014). Biotransformation of 6:2 fluorotelomer alcohol (6:2 FTOH) by a wood-rotting fungus. Environ. Sci. Technol. 48, 4012-4020. doi: 10.1021/es4057483

Uhlík, O., Jecná, K., Leigh, M. B., Macková, M., and Macek, T. (2009). DNAbased stable isotope probing: a link between community structure and function. Sci. Total Environ. 407, 3611-3619. doi: 10.1016/j.scitotenv.2008. 05.012

Uqab, B., Mudasir, S., and Nazir, R. (2016). Review on bioremediation of pesticides. J Bioremed. Biodeg. 7:343. doi: 10.4172/2155-6199.1000343

Venkatesan, A. K., and Halden, R. U. (2014). Wastewater treatment plants as chemical observatories to forecast ecological and human health risks of manmade chemicals. Sci. Rep. 4:3731. doi: 10.1038/srep03731

Vo, N. X. Q., Kang, H.-J., and Park, J.-H. (2007). Functional metagenomics using stable isotope probing: a review. Environ. Eng. Res. 12, 231-237. doi: 10.4491/eer.2007.12.5.231

Von Der Trenck, K. T., Konietzka, R., Biegel-Engler, A., Brodsky, J., Hadicke, A., Quadflieg, A., et al. (2018). Significance thresholds for the assessment of contaminated groundwater: perfluorinated and polyfluorinated chemicals. Environ. Sci. Europe 30:19. doi: 10.1186/s12302-018-0142-4

Wang, N., Szostek, B., Buck, R. C., Folsom, P. W., Sulecki, L. M., and Gannon, J. T. (2009). 8-2 fluorotelomer alcohol aerobic soil biodegradation: 
pathways, metabolites, and metabolite yields. Chemosphere 75, 1089-1096. doi: 10.1016/j.chemosphere.2009.01.033

Wang, X., Schuster, J., Jones, K. C., and Gong, P. (2018). Occurrence and spatial distribution of neutral perfluoroalkyl substances and cyclic volatile methylsiloxanes in the atmosphere of the Tibetan Plateau. Atmos. Chem. Phys. 18:8745. doi: 10.5194/acp-18-8745-2018

Weiner, B., Yeung, L. W., Marchington, E. B., D’agostino, L. A., and Mabury, S. A. (2013). Organic fluorine content in aqueous film forming foams (AFFFs) and biodegradation of the foam component 6:2 fluorotelomermercaptoalkylamido sulfonate (6: 2 FTSAS). Environ. Chem. 10, 486-493. doi: 10.1071/EN13128

Xiao, F., Simcik, M. F., and Gulliver, J. S. (2012). Perfluoroalkyl acids in urban stormwater runoff: influence of land use. Water Res. 46, 6601-6608. doi: 10.1016/j.watres.2011.11.029

Xiao, F., Simcik, M. F., Halbach, T. R., and Gulliver, J. S. (2015). Perfluorooctane sulfonate (PFOS) and perfluorooctanoate (PFOA) in soils and groundwater of a US metropolitan area: migration and implications for human exposure. Water Res. 72, 64-74. doi: 10.1016/j.watres.2014.09.052

Yamada, T., Taylor, P. H., Buck, R. C., Kaiser, M. A., and Giraud, R. J. (2005). Thermal degradation of fluorotelomer treated articles and related materials. Chemosphere 61, 974-984. doi: 10.1016/j.chemosphere.2005. 03.025

Yang, Y., Zhao, Y., Liu, R., and Morgan, D. (2018). Global development of various emerged substrates utilized in constructed wetlands. Bioresour. Technol. 261, 441-452. doi: 10.1016/j.biortech.2018.03.085

Yates, B. J., Darlington, R., Zboril, R., and Sharma, V. K. (2014). High-valent iron-based oxidants to treat perfluorooctanesulfonate and perfluorooctanoic acid in water. Environ. Chem. Lett. 12, 413-417. doi: 10.1007/s10311-0140463-5
Yi, L., Chai, L., Xie, Y., Peng, Q., and Peng, Q. (2016). Isolation, identification, and degradation performance of a PFOA-degrading strain. Genet. Mol. Res. 15, 235-246. doi: 10.4238/gmr.15028043

Yu, X., Nishimura, F., and Hidaka, T. (2018). Impact of long-term perfluorooctanoic acid (PFOA) exposure on activated sludge process. Water Air Soil Pollut. 229:134. doi: 10.1007/s11270-018-3760-y

Zhang, D., Zhang, W., and Liang, Y. (2020). Bacterial community in a freshwater pond responding to the presence of perfluorooctanoic acid (PFOA). Environ. Technol. 41, 3646-3656. doi: 10.1080/09593330.2019.1616828

Zhang, Q., Deng, S., Yu, G., and Huang, J. (2011). Removal of perfluorooctane sulfonate from aqueous solution by crosslinked chitosan beads: sorption kinetics and uptake mechanism. Bioresour. Technol. 102, 2265-2271. doi: 10.1016/j.biortech.2010.10.040

Zhang, W., Zhang, D., Zagorevski, D. V., and Liang, Y. (2019). Exposure of Juncus effusus to seven perfluoroalkyl acids: uptake, accumulation and phytotoxicity. Chemosphere 233, 300-308. doi: 10.1016/j.chemosphere.2019.05.258

Conflict of Interest: The authors declare that the research was conducted in the absence of any commercial or financial relationships that could be construed as a potential conflict of interest.

Copyright (C) 2021 Shahsavari, Rouch, Khudur, Thomas, Aburto-Medina and Ball. This is an open-access article distributed under the terms of the Creative Commons Attribution License (CC BY). The use, distribution or reproduction in other forums is permitted, provided the original author(s) and the copyright owner(s) are credited and that the original publication in this journal is cited, in accordance with accepted academic practice. No use, distribution or reproduction is permitted which does not comply with these terms. 